\title{
Erratum to: Impact of HIV-1 infection on the feto-maternal crosstalk and consequences for pregnancy outcome and infant health
}

\author{
Marcus Altfeld $^{1}$ - Madeleine J. Bunders ${ }^{1,2,3}$
}

Published online: 18 August 2016

(C) Springer-Verlag Berlin Heidelberg 2016

\section{Erratum to: Semin Immunopathol}

DOI 10.1007/s00281-016-0578-9

As originally published, the article "Impact of HIV-1 infection on the feto-maternal crosstalk and consequences for pregnancy outcome and infant health" contained an incomplete version of Fig. 1. This error has since been rectified; the correct illustration is also shown here.

The online version of the original article can be found at doi:10.1007 /s00281-016-0578-9.

\footnotetext{
Madeleine J. Bunders

m.j.bunders@amc.uva.nl

1 Department of Virus Immunology, Heinrich-Pette Institute, Leibniz Institute for Experimental Virology, Hamburg, Germany

2 Department of Experimental Immunology, University of Amsterdam (UvA), Academic Medical Center (AMC),

Amsterdam, The Netherlands

3 Emma Childrens Hospital,UvA, AMC, Amsterdam, The Netherlands
} 


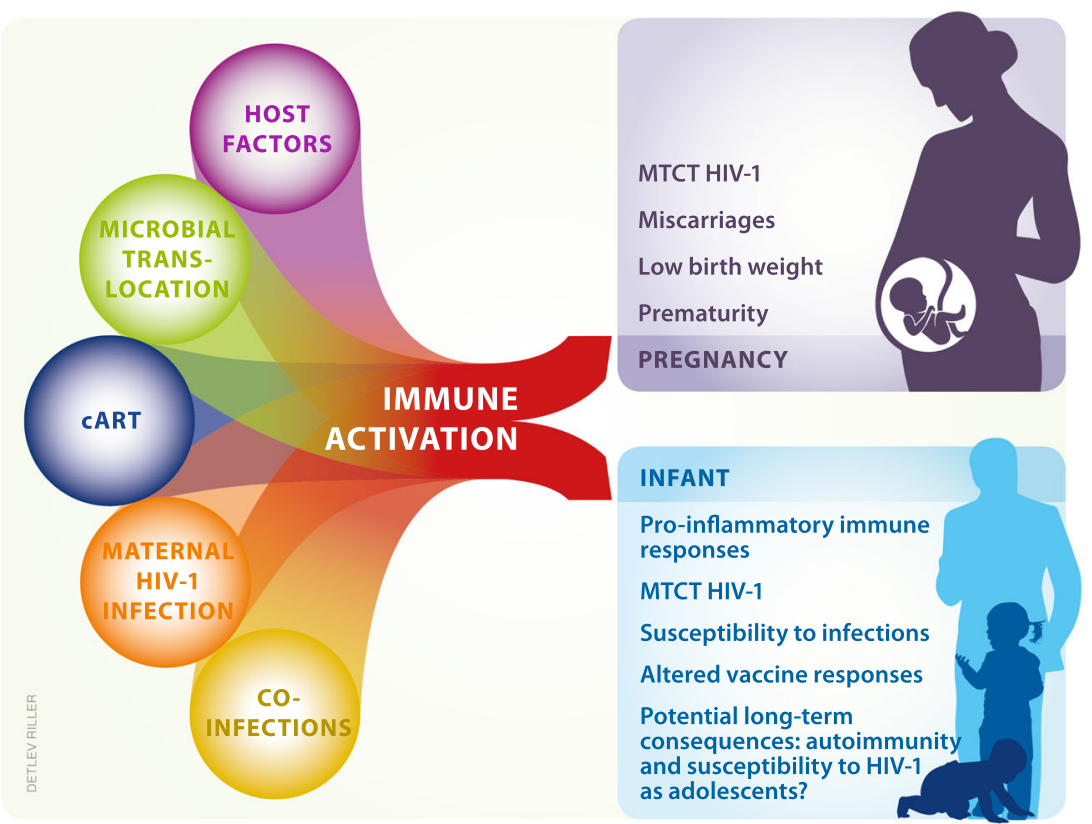

Fig. 1 Implications of HIV-1-related immune activation for pregnancy outcome and the infants of HIV-1-infected women 